\title{
Treatment Approaches for Diabetes and Dyslipidemia
}

\author{
Mingyuan Wu Timothy J. Lyons \\ Harold Hamm Oklahoma Diabetes Center and Section of Endocrinology and Diabetes, University of Oklahoma \\ Health Sciences Center, Oklahoma City, Okla., USA
}

\section{Key Words}

Diabetes $\cdot$ Dyslipidemia $\cdot$ Nuclear magnetic resonance spectroscopy $\cdot$ Residual risk

\begin{abstract}
Background: Dyslipidemia is an important risk factor for cardiovascular complications in persons with diabetes. Lowdensity lipoprotein-cholesterol (LDL-C) is the 'cornerstone' for assessment of lipoprotein-associated risk. However, LDLC levels do not reflect the classic 'diabetic dyslipidemia' of hypertriglyceridemia and low high-density lipoprotein-cholesterol (HDL-C). Measurements of plasma apolipoprotein B100 concentrations and non-HDL-C may improve the definition of dyslipidemia. Statins, nicotinic acid and fibrates have roles in treating dyslipidemia in diabetes. Residual risk (i.e. risk that persists after correction of 'conventional' plasma lipoprotein abnormalities) is a new concept in the role of dyslipidemia in the pathogenesis of diabetic vascular complications. For example, regardless of plasma levels, lipoprotein extravasation through a leaking retinal blood barrier and subsequent modification may be crucial in the development of diabetic retinopathy. The current approach to the management of dyslipidemia in diabetes is briefly summarized, followed by a discussion of new concepts of residual
\end{abstract}

risk and emerging lipoprotein-related mechanisms for vascular disease in diabetes. Conclusions: Effective treatments must correct adverse quantitative plasma lipoprotein levels and a spectrum of qualitative abnormalities in plasma and tissue, as well as the processes by which lipoproteins and cells interact at the sites of disease.

Copyright $\odot 2011$ S. Karger AG, Basel

\section{Assessment and Treatment of Dyslipidemia in Diabetes: Current Approaches}

Measurement of Lipid-Related Cardiovascular Risk in Diabetic Patients

Current guidelines recommend low-density lipoprotein-cholesterol (LDL-C) as the primary metric of cardiovascular risk in people with diabetes $[1,2]$. Over the past 15 years, several new measures of cardiovascular risk have become available, some of which may be superior to current approaches.

LDL-C is the 'cornerstone' for assessment of lipoprotein-related cardiovascular risk. Elevated LDL-C is an established risk factor for cardiovascular disease [3] and may have enhanced significance in diabetes, where smaller LDL particles result in higher particle numbers per

\section{KARGER}

Fax +4161306 1234

E-Mail karger@karger.ch

www.karger.com (c) 2011 S. Karger AG, Basel

$1663-2818 / 11 / 0767-0076 \$ 38.00 / 0$

Accessible online at:

www.karger.com/hrp
Timothy J. Lyons, MD, FRCP

Harold Hamm Oklahoma Diabetes Center, University of Oklahoma Health Sciences Center, Department of Endocrinology and Diabetes

920 Stanton L. Yound Blvd., WP-1345, Oklahoma City, OK 73104 (USA)

Tel. +1 405271 3616, E-Mail timothy-lyons@ouhsc.edu 
Table 1. Target values for LDL-C, non-HDL-C and ApoB100 in people with high and very high vascular disease risk

\begin{tabular}{llll}
\hline Risk Category & $\begin{array}{l}\text { LDL-C } \\
\mathrm{mg} / \mathrm{dl}(\mathrm{mmol} / \mathrm{l})\end{array}$ & $\begin{array}{l}\text { Non-HDL-C } \\
\mathrm{mg} / \mathrm{dl}(\mathrm{mmol} / \mathrm{l})\end{array}$ & $\begin{array}{l}\text { ApoB100 } \\
\mathrm{mg} / \mathrm{dl}(\mu \mathrm{mol} / \mathrm{l})\end{array}$ \\
\hline $\begin{array}{l}\text { Highest risk: CVD or DM + one major factor } \\
\text { High risk: DM only, or two major factors }\end{array}$ & $<70(1.81)$ & $\begin{array}{l}<100(2.58) \\
<130(3.36)\end{array}$ & $<80(1.60)$ \\
\hline
\end{tabular}

Target value of LDL-C is $<70 \mathrm{mg} / \mathrm{dl}(1.81 \mathrm{mmol} / \mathrm{l})$ for patients with the highest risk and $<100 \mathrm{mg} / \mathrm{dl}(2.58$ $\mathrm{mmol} / \mathrm{l})$ for those with high risk; corresponding target values for non-HDL-C are $<100 \mathrm{mg} / \mathrm{dl}(2.58 \mathrm{mmol} / \mathrm{l})$ and $<130 \mathrm{mg} / \mathrm{dl}(3.36 \mathrm{mmol} / \mathrm{l})$, and for ApoB100 they are $<80 \mathrm{mg} / \mathrm{dl}(1.60 \mathrm{mmol} / \mathrm{l})$ and $<130 \mathrm{mg} / \mathrm{dl}(1.8 \mathrm{mmol} / \mathrm{l})$. $\mathrm{CVD}=$ Cardiovascular disease $; \mathrm{DM}=$ diabetes mellitus.

unit of cholesterol [4]. Lowering LDL-C is effective in the primary and secondary prevention of diabetic vascular complications $[5,6]$. However, LDL-C has limitations: it is a derived value (from the Friedewald equation), and it progressively underestimates LDL-C as triglyceride levels rise [7]. Further, LDL-C does not reflect the classic 'diabetic dyslipidemia', which consists of hypertriglyceridemia and low levels of high-density lipoprotein-cholesterol (HDL-C) $[8,9]$.

One alternate approach to LDL-C measurement is to measure molar concentrations of LDL particles by nuclear magnetic resonance (NMR) spectroscopy. The usefulness of this approach, which brings the additional ability to measure large- and small-diameter subclasses (the latter being more atherogenic), has been supported in epidemiologic studies [10,11]. NMR analysis is clinically available, but it is expensive and can only be ordered from a limited number of centers.

Measuring plasma apolipoprotein B100 (ApoB100) concentration may improve the definition of risk. Because there is only one ApoB100 molecule on each LDL, intermediate-density lipoprotein and very-low-density lipoprotein (VLDL) particle, its molar concentration reflects the combined molar concentrations of these three atherogenic particle classes [12]. Fasting is not necessary for ApoB100 measurement, since chylomicrons contain a different 'B' apolipoprotein (ApoB48) [13]. The ApoB100 assay is standardized, but it is not widely available.

Another valuable measure that also reflects all ApoB100-containing (and hence atherogenic) particles is 'non-HDL-C'. This is a low-cost metric that is available from conventional lipid profiles, and is determined by subtracting $\mathrm{HDL}-\mathrm{C}$ from the total cholesterol value. This measurement is recommended by the National Cholesterol Education Panel - Adult Treatment Panel III (NCEP/
ATP III) as the secondary goal after LDL-C has been brought to target, and it may be superior to LDL-C for predicting risk of cardiovascular disease [14]. As with the measurement of ApoB100, fasting is not necessary for the determination of non-HDL-C because chylomicrons contain negligible cholesterol.

Plasma triglycerides have been identified as significant univariate, but not multivariate, predictors of cardiovascular disease; the difference is presumably due to confounding effects of HDL-C [8]. Whereas increased triglyceride levels are associated with activation of the coagulation cascade, no studies have demonstrated that lowering triglycerides has an independent effect on cardiovascular event rates.

HDL-C levels demonstrate a strong inverse association with cardiovascular risk. HDL has numerous functions including anti-inflammatory, antioxidant, and antithrombotic effects $[12,15]$ in addition to reverse cholesterol transport. It is also an acute-phase reactant. To date, interventions to raise $\mathrm{HDL}-\mathrm{C}$, which are not very effective, have not been shown to reduce cardiovascular risk [16]. As with other lipoproteins, the functionality (or quality) of HDL must be considered in addition to quantitative measures, and HDL function may be impaired in the presence of diabetes.

\section{Treatment Targets and Goals}

A detailed summary of current treatment targets is beyond the scope of this review; however, excellent reviews have been recently published by Colwell [5], the NCEP/ ATP III [14], and Brunzell et al. [17]. Table 1 summarizes target values for LDL-C, non-HDL-C, and ApoB100 in people with diabetes who are considered to have 'high' or 'very high' vascular disease risk. 
Pharmacologic Interventions

Statins (3-Hydroxy-3-Methyl-Glutaryl-CoA

Reductase Inhibitors)

The benefits of statin treatment in the primary and secondary prevention of cardiovascular disease have been unequivocally demonstrated. These medications may be effective in patients with diabetes because the atherogenicity of LDL particles is increased in diabetes (see below). The primary prevention Collaborative Atorvastatin Diabetes Study (CARDS) showed a relative risk reduction of $37 \%$ over 5 years of statin treatment in patients with type 2 diabetes [18]. Diabetes increases cardiovascular risk 2- to 4-fold [19] and a relative risk reduction of $50-75 \%$ would be necessary to restore the risk in people with diabetes to 'normal'. This observation underlies the concept of residual risk as reviewed below. Importantly, atherosclerosis is a disease of the blood vessel wall, and drugs with effects at the actual site of disease, not just on plasma lipoprotein concentrations, may be the most beneficial. The 'pleiotropic' effects of statins are substantial: they reduce the lipid content of plaque core, decrease the number of inflammatory cells, decrease matrix metalloproteinase activity and tissue factor activation, and inhibit plaque rupture $[20,21]$.

\section{Nicotinic Acid}

Nicotinic acid is effective in reducing VLDL production, reducing triglycerides and raising HDL-C. It has modest beneficial effects on LDL-C and proven beneficial effects on clinical outcomes. Side effects including flushing, hyperglycemia, dyspepsia, hepatic toxicity, and gout are usually manageable, especially with newer sustainedrelease preparations. Considering the potential benefits, nicotinic acid is underutilized.

\section{Fibrates}

Fibrates, which lower plasma triglycerides, might seem like a logical first-line treatment for dyslipidemia in patients with diabetes. This question was addressed by the Fenofibrate Intervention and Event Lowering in Diabetes (FIELD) study, a primary prevention study in which almost 10,000 type 2 diabetic patients were randomized to receive either placebo or fenofibrate $200 \mathrm{mg}$ daily [22]. Patients were followed for 5 years, and the data were analyzed on an 'intent-to-treat' basis. Fenofibrate failed to reduce the primary outcome, a composite of coronary events. There was a notable reduction in the secondary endpoint of total cardiovascular events, and the addition of statin treatment for patients in both randomization groups may have masked a larger effect of fenofibrate.
Overall, the study did not support a recommendation for increasing the use of fibrates in people with diabetes. A more recent FIELD study reported a beneficial effect of fenofibrate on retinopathy progression [23].

\section{New Concepts: Residual Risk, Qualitative Abnormalities of Lipoproteins, Extravasated Lipoproteins in the Eye and beyond the Arterial Intima}

Diabetes results in different interactive stresses on tissues at the cellular level. Among these stresses are elevated glucose concentrations, increased oxidative stress, increased carbonyl stress, exposure to modified (glycated and oxidized) lipoproteins, insulin resistance, increased inflammation, exposure to glycation and advanced glycation products and reactive nitrogen species [24]. In patients with type 2 diabetes, many of these stresses and metabolic abnormalities may have been present for decades before diagnosis. Given these considerations, it is perhaps not surprising that correction of dyslipidemia over a period of a few years fails to restore cardiovascular risk to normal.

Recently the term 'residual risk' has been used in the context of plasma lipoprotein abnormalities that persist after conventional treatment goals have been reached [25]. Many factors contribute to lipoprotein-related residual risk in patients with diabetes. Some risk factors are qualitative lipoprotein abnormalities that are not detected in conventional lipoprotein profiles. Examples include altered lipoprotein particle size distribution, altered apolipoprotein complement, apolipoprotein polymorphisms, modification of particles by glycation and oxidation, and altered activity of lipoprotein-associated enzymes [26]. Furthermore, as noted above, many of the pathogenic effects of lipoproteins occur not while they are in the circulation, but rather after extravasation into vascular walls, and not only in the arteries but also in the specialized microcirculatory beds of the eye and kidney.

Diabetic retinopathy provides an interesting example for these concepts. We demonstrated associations between NMR-defined plasma lipoprotein subclasses and the severity of retinopathy in type 1 diabetic patients, particularly men, in the Diabetes Control and Complications Trial (DCCT) [27]. The associations were statistically highly significant, but only moderate in magnitude. More recently, in studies of human retinae obtained postmortem from nondiabetic and type 2 diabetic persons, we demonstrated the presence of large quantities of ex- 


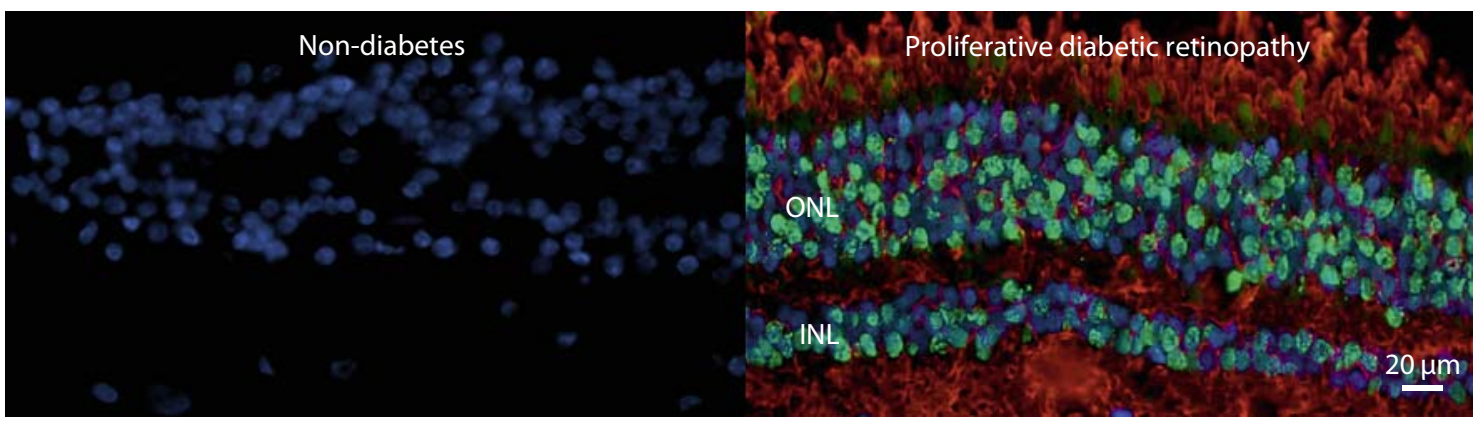

Fig. 1. Oxidized LDL and TUNEL-positive cells are absent in the retina from a nondiabetic subject, but present in the retina from a subject with type 2 diabetes and proliferative diabetic retinopathy. Retinal sections were stained with anti-TUNEL antibody (green), antibody to oxidized LDL (red), and antibody to DAPI (blue). INL = Inner nuclear layer; ONL = outer nuclear layer; TUNEL = terminal deoxynucleotidyl transferase dUTP nick end labeling; DAPI = 4',6-diamidino-2-phenylindole (fluorescent stain).

travasated ApoB100 and oxidized LDL in retinal tissues from diabetic subjects. The extent of staining increased with severity of retinopathy, but it was entirely absent in healthy retinae from nondiabetic individuals [28].

We hypothesize that retinal capillary leakage in diabetes results in extravasation of LDL, its subsequent modification by glycation and severe oxidation within the retinal tissue. This observation suggests that lipoproteins from plasma may play a central, and heretofore unrecognized, role in propagating retinal injury, even though the associations of plasma lipoproteins with the severity of retinopathy, although statistically significant, are relatively weak in magnitude (fig. 1). Oxidized LDL is toxic to many cell types, including vascular cells, and may propagate retinal injury [28]. These observations support the concept that plasma lipoproteins (which we can study relatively easily) may modulate disease risk, but extravasated lipoproteins (much less accessible and likely significantly modified) are the direct mediators of disease. Effective treatments must thus correct not only adverse quantitative plasma lipoprotein levels, but a spectrum of qualitative abnormalities in both plasma and tissues, and the processes by which lipoproteins and cells interact at the sites of disease.

\section{Conclusions}

Diabetes and its complications are epidemic worldwide. Qualitative, in addition to quantitative, lipoprotein abnormalities are central in mediating vascular injury. In many settings, the disease process proceeds unchecked for years or decades before detection. Financial costs, as well as morbidity and mortality associated with the complications of diabetes, threaten to overcome health-care budgets. Better identification of risk factors, better understanding of disease mechanisms and development of effective screening, prevention and treatment strategies are critical in meeting these challenges.

\section{Acknowledgments}

This study was supported in part by a grant P20RR024215 from the National Center for Research Resources (NCRR) entitled 'Mentoring Diabetes Research in Oklahoma', and by a grant to T.J.L. from the Oklahoma Center for the Advancement of Science and Technology, HR08-67.

\section{Disclosure Statement}

M.W. declares no conflict of interest.

T.J.L. is an investigator in clinical trials sponsored by NephroGenex, MacroGenics, Novartis, Pfizer, Bristol-Myers Squibb, Corcept Therapeutics, Novo Nordisk and VeraLight. He received an honorarium from Pfizer in association with his presentation and resulting manuscript for the proceedings for the 41st International Symposium sponsored by Pfizer.

Production logistics including collection of manuscripts, assistance to editors, obtaining reprint permissions, graphic design and layout were provided by CMM Global. 


\section{References}

$>1$ Buse JB, Ginsberg HN, Bakris GL, Clark NG, Costa F, Eckel R, Fonseca V, Gerstein HC, Grundy S, Nesto RW, Pignone MP, Plutzky J, Porte D, Redberg R, Stitzel KF, Stone NJ; American Heart Association; American Diabetes Association: Primary prevention of cardiovascular diseases in people with diabetes mellitus: a scientific statement from the American Heart Association and the American Diabetes Association. Circulation 2007; 115:114-126.

$>2$ Buse JB, Ginsberg HN, Bakris GL, Clark NG, Costa F, Eckel R, Fonseca V, Gerstein HC, Grundy S, Nesto RW, Pignone MP, Plutzky J, Porte D, Redberg R, Stitzel KF, Stone NJ; American Heart Association; American Diabetes Association: Primary prevention of cardiovascular diseases in people with diabetes mellitus: a scientific statement from the American Heart Association and the American Diabetes Association. Diabetes Care 2007;30:162-172.

$>3$ Martin MJ, Hulley SB, Browner WS, Kuller LH, Wentworth D: Serum cholesterol, blood pressure, and mortality: implications from a cohort of 361,662 men. Lancet 1986;2:933936.

4 Garvey WT, Kwon S, Zheng D, Shaughnessy S, Wallace P, Hutto A, Pugh K, Jenkins AJ, Klein RL, Liao Y: Effects of insulin resistance and type 2 diabetes on lipoprotein subclass particle size and concentration determined by nuclear magnetic resonance. Diabetes 2003;52:453-462.

$>5$ Colwell JA: Prevention of diabetes complications. Clin Cornerstone 1998;1:58-71.

$\checkmark 6$ Irons BK, Kroon LA: Lipid management with statins in type 2 diabetes mellitus. Ann Pharmacother 2005;39:1714-1719.

$>7$ Sniderman AD, Blank D, Zakarian R, Bergeron J, Frohlich J: Triglycerides and small dense LDL: the twin Achilles heels of the Friedewald formula. Clin Biochem 2003; 36:499-504.

-8 Elam MB, Hunninghake DB, Davis KB, Garg R, Johnson C, Egan D, Kostis JB, Sheps DS, Brinton EA: Effect of niacin on lipid and lipoprotein levels and glycemic control in patients with diabetes and peripheral arterial disease: the ADMIT study: a randomized trial. Arterial Disease Multiple Intervention Trial. JAMA 2000;284:1263-1270.

$>9$ Oki JC: Dyslipidemias in patients with diabetes mellitus: classification and risks and benefits of therapy. Pharmacotherapy 1995; 15:317-337.
10 Lyons TJ, Jenkins AJ, Zheng D, Klein RL, Otvos JD, Yu Y, Lackland DT, McGee D, McHenry MB, Lopes-Virella M, Garvey WT; DCCT/EDIC Research Group: Nuclear magnetic resonance-determined lipoprotein subclass profile in the DCCT/EDIC cohort: associations with carotid intima-media thickness. Diabet Med 2006;23:955-966.

11 Soedamah-Muthu SS, Chang YF, Otvos J, Evans RW, Orchard TJ; Pittsburgh Epidemiology of Diabetes Complications Study: Lipoprotein subclass measurements by nuclear magnetic resonance spectroscopy improve the prediction of coronary artery disease in type 1 diabetes. A prospective report from the Pittsburgh Epidemiology of Diabetes Complications Study. Diabetologia 2003;46: 674-682.

12 Jenkins AJ, Best JD, Klein RL, Lyons TJ: 'Lipoproteins, glycoxidation and diabetic angiopathy.' Diabetes Metab Res Rev 2004;20: 349-368.

13 Verseyden C, Meijssen S, Castro Cabezas M: Postprandial changes of apoB-100 and apoB48 in TG rich lipoproteins in familial combined hyperlipidemia. J Lipid Res 2002;43: 274-280.

14 Expert Panel on Detection, Evaluation, and Treatment of High Blood Cholesterol in Adults. Executive summary of the Third Report of the National Cholesterol Education Program (NCEP) expert panel on detection, evaluation, and treatment of high blood cholesterol in adults (Adult Treatment Panel III). JAMA 2001;285:2486-2497.

15 Andersson LO: Pharmacology of apolipoprotein A-1. Curr Opin Lipidol 1997;8:225228.

16 Briel M, Ferreira-Gonzalez I, You JJ, Karanicolas PJ, Akl EA, Wu P, Blechacz B, Bassler D, Wei X, Sharman A, Whitt I, Alves da Silva S, Khalid Z, Nordmann AJ, Zhou Q, Walter SD, Vale N, Bhatnagar N, O’Regan C, Mills EJ, Bucher HC, Montori VM, Guyatt GH: Association between change in high density lipoprotein cholesterol and cardiovascular disease morbidity and mortality: systematic review and meta-regression analysis. Br Med J 2009;338:b92.

17 Brunzell JD, Davidson M, Furberg CD, Goldberg RB, Howard BV, Stein JH, Witztum JL: Lipoprotein management in patients with cardiometabolic risk: consensus conference report from the American Diabetes Association and the American College of Cardiology Foundation. J Am Coll Cardiol 2008;51:1512-1524.

- 18 Colhoun HM, Betteridge DJ, Durrington PN, Hitman GA, Neil HA, Livingstone SJ, Thomason MJ, Fuller JH, CARDS Investigators: Rapid emergence of effect of atorvastatin on cardiovascular outcomes in the Collaborative Atorvastatin Diabetes Study (CARDS). Diabetologia 2005;48:2482-2485.
19 National Diabetes Fact Sheet. Centers for Disease Control 2007. Available at: http:// www.cdc.gov/diabetes/pubs/pdf/ndfs_2007. pdf. Accessed October 8, 2007.

20 Westerweel PE, Verhaar MC, Rabelink TJ: Pleiotropic effects of statins (in Dutch). Ned Tijdschr Geneeskd 2004;148:1431-1435.

21 Davignon J: Beneficial cardiovascular pleiotropic effects of statins. Circulation 2004; 109(23 suppl 1):III39-III43.

22 Keech A, Simes RJ, Barter P, Best J, Scott R, Taskinen MR, Forder P, Pillai A, Davis T, Glasziou P, Drury P, Kesaniemi YA, Sullivan D, Hunt D, Colman P, d'Emden M, Whiting M, Ehnholm C, Laakso M; FIELD study investigators: Effects of long-term fenofibrate therapy on cardiovascular events in 9795 people with type 2 diabetes mellitus (the FIELD study): randomised controlled trial. Lancet 2005;366:1849-1861.

23 Keech AC, Mitchell P, Summanen PA, O’Day J, Davis TM, Moffitt MS, Taskinen MR, Simes RJ, Tse D, Williamson E, Merrifield A, Laatikainen LT, d'Emden MC, Crimet DC, O'Connell RL, Colman PG, FIELD study investigators: Effect of fenofibrate on the need for laser treatment for diabetic retinopathy (FIELD study): a randomised controlled trial. Lancet 2007;370:1687-1697.

24 Yu Y, Lyons TJ: A lethal tetrad in diabetes: hyperglycemia, dyslipidemia, oxidative stress, and endothelial dysfunction. Am J Med Sci 2005;330:227-232.

-25 Fruchart JC, Sacks F, Hermans MP, Assmann G, Brown WV, Ceska R, Chapman MJ, Dodson PM, Fioretto P, Ginsberg HN, Kadowaki T, Lablanche JM, Marx N, Plutzky J, Reiner Z, Rosenson RS, Staels B, Stock JK, Sy R, Wanner C, Zambon A, Zimmet P: The Residual Risk Reduction Initiative: a call to action to reduce residual vascular risk in patients with dyslipidemia. Am J Cardiol 2008; 102: $1 \mathrm{~K}-34 \mathrm{~K}$.

26 Taskinen MR: Quantitative and qualitative lipoprotein abnormalities in diabetes mellitus. Diabetes 1992;41(suppl 2):12-17.

27 Lyons TJ, Jenkins AJ, Zheng D, Lackland DT, McGee D, Garvey WT, Klein RL: Diabetic retinopathy and serum lipoprotein subclasses in the DCCT/EDIC cohort. Invest Ophthalmol Vis Sci 2004;45:910-918.

28 Wu M, Chen Y, Wilson K, Chirindel A, Ihnat MA, Yu Y, Boulton ME, Ma JX, Szweda LI, Lyons TJ: Intra-retinal leakage and oxidation of LDL in diabetic retinopathy. Invest Ophthalmol Vis Sci 2008;49:2679-2686. 